\title{
Analysis and Reflection on the Relationship Between the Vision of Embodied Cognitive and VR Educational Games
}

\author{
Ling $\mathrm{He}^{1, a}$, Qian Shen ${ }^{2, b}$ and Rui $\mathrm{Li}^{3, \mathrm{c}}$ \\ 1'Jiangxi Science \& Technology Normal University, NanChang, China \\ ${ }^{2}$ Jiangxi Science \& Technology Normal University, NanChang, China \\ ${ }^{3}$ Jiangxi Science \& Technology Normal University , NanChang, China \\ aynlynhe126@126.com, b1764349539@qq.com, c18091998228@163.com
}

\begin{abstract}
Keywords: VR educational game; physical cognition; experiential learning; body movement. Abstract.This paper summarizes the research background, research problems and research status of VR educational games and embodied cognition. It also analyzes the relationship between VR educational games and embodied cognition theory -- experiential learning from the perspective of body. The literature analysis was used to study the physical form and body movements of VR education games and physical cognitive perspectives, and at the same time to study the combination of VR educational games and embodied cognition.
\end{abstract}

\section{Introduction}

\section{Background of Research}

Since 1980s, the study of "embodied cognition" in the West has become the focus of attention, which belongs to the category of psychology. Embodied cognition emphasizes that the process of cognitive is not an abstract symbol processing, but the physical properties of the body and the experience of the sensorimotor system. ${ }^{[1]}$ The theory of embodied cognition initiates the liberation and regression of body in learning, and attaches importance to learners' experiential learning. VR educational games also attach importance to learners' situational teaching, along with the actions and changes of learners' body shape. Soon, globally, embodied cognition has been integrated in various fields, including artificial intelligence, psychology, morality, education and so on. The combination of embodied cognition theory and education is relatively rare. This article mainly combines the theory of embodied cognition and a kind of education ---VR educational game, and studies the significance of experiential learning and the change of body shape. Now it has begun to study some educational systems that apply virtual reality technology and have begun to apply to the college at abroad. If the combination of two parties and body language has been attached importance to, it will greatly improve the teaching level of VR educational games.

\section{Research Problems}

Based on the theory of embodied cognition, what should be the framework of the VR educational game in the physical perspective? How do physical movements strengthen the sense of immersion and participation of VR educational games? How to strengthen its experience learning? And the game mechanism is integrated into the VR educational game, including plot design, card design, incentive mechanism, competition mechanism and so on.

\section{Research Methods---Literature Analysis}

The first part is the content analysis and literature review of the mainstream research on international VR educational game and embodied cognition, and summarizes the relationship and influence of VR educational games and embodied cognition at home and abroad. The second part is the retrieval of the Web of Science library and CNKI domestic and international literature. The main literature sample for international relevant professional journals and Academic Forum: "PROCEEDINGS GAMES BASED LEARNING (4th 5th, and 6th)", "COMPUTERS EDUCATION","THE JOURNAL of 
LEARNING SCIENCE", which is the related research papers, and other educational games at home and abroad and the theory based on the important works of embodied cognition on the impact of education. This paper systematically expounds the development direction of VR educational game and the comprehensive liberation and regression of body based on embodied cognition.

\section{Embodied Cognition}

\section{Definitions of Embodied Cognition}

Embodied Cognition is also known as body cognition. Haosheng Ye believes that the central meaning of embodied cognition is that cognition or mind is mostly determined by the form of body movements.

${ }^{[2]}$ We should pay more attention to both the function of the body and the connection between the body and the environment.

\section{Domestic Research Status of Embodied Cognition}

In China, embodied cognition research has focused on the development significance and impact on the field of philosophy, cognitive psychology, linguistics, education. When traced out contention problems of the cognitive theory and explore the relationship between body and mind, now we gradually began to demonstrate the embodied cognition theory from the view of discipline. On the issue of "the impact of embodied cognition on education", studies were few but have begun in the past few years. Earlier in China on embodied cognition journal articles have the Xianjun Xu's ${ }^{[3]}$ "Body Phenomenology Critique of Cognitive Science" and Wei Meng's ${ }^{[4]}$ "Melo Ponty's Embodied Cognitive Science Thought and Its Implication of Cognition". Both are mainly the research of embodied cognition and philosophy combined. The research of Wei Meng and Xianjun Xu greatly promoted the interdisciplinary cooperation between phenomenology and cognitive science in China, and found a new research direction based on the dialogue between philosophy and science.

Qiwei Li's ${ }^{[5]}$ "controversy between cognitive revolution" and the "second generation of" cognitive science " as the representative, Chinese began to connect the embodied cognition with psychology. The article tells the story of second generation cognitive science that body becomes the core feature of research. At the same time it systematically explain and the macro grasp the field of cognitive science, which inspire us to think the relationship between physical and mental, physiological reductionism, artificial intelligence. Jun Ding and Haosheng Ye are the famous experts on cognitive psychology research in China. Jun Ding and Wei Chen introduced the "mirror neuron" and the theory of body imitation which was induced by it. Haosheng Ye, come from Guangzhou University, and other research teams have studied the embodied cognition from the perspective of psychology. The research results have been published in the major journals of psychology. The most important is that Haosheng Ye involved empirical research, which pushed the embodied cognition of domestic psychology to a climax. Such as "Embodied Cognition: Cognitive Psychology", "the New Orientation in Western Psychology Embodied Cognition Tesearch Trends" and "Theoretical Psychology Thinking Based on Embodied Cognition "[6] and other articles from a psychological perspective make a comprehensive analysis of the embodied cognition, he stressed three central meaning of embodied cognition. ${ }^{\text {[7] }}$ However, the disunity of research perspective and the standpoint of research will inevitably hinder the process and make it face challenges, such as vigilance of returning to the new form of behaviorism. Embodied cognition has not only become a hot topic in the field of philosophy and cognitive psychology, but also in the field of cognitive linguistics in China.

From the educational point of view, or in the perspective of educational technology, there are few studies on embodied cognition. Most of them are the combination between Chinese, mathematics, physics and other specific subjects based on the embodied cognition theory, and research and articles related to educational technology are only few. Qian Zhou, Anlan Qin and Yunyuan Li, also study the enlightenment of embodied cognition on preschool education and its application in the English Teaching of young children from the theoretical level of embodied cognition. Suzhou University professor Mengcheng Zhao proposed four future research approaches. ${ }^{[8]}$ 
Throughout the whole, although article about the embodied cognition has an increasing trend in the number of literature, the objective phenomenon shows that the number of study of domestic scholars are gradually increasing. But from the prospect of the literature content, embodied cognition research remains to be further extended on the field of psychology, cognitive linguistics and education, especially in the field of education its worth should take the value of mining. Research in the field of embodied cognition has increased year by year, but its essence is little research on specific body posture, which requires much energy to study.

\section{Abroad Research Status of Embodied Cognition}

In 1980s, foreign country develop rapidly affected by foreign embodied cognition trend. Theory and practice of the development "embodied cognition", "the body mind" and "body imitation" have make the concept of embodied philosophy in-depth and impact psychology, computer science, social science, pedagogy and Linguistics etc. Husserl, Heidegger and Piaget first started the study of physical cognition, and put forward the theory of phenomenology and the relevance of meaning. Margaret Wilson proposed six major ideas of physical cognition. ${ }^{[9]}$ First of all, Theron believes that cognitive stem from the interaction in the body world. Mind and cognition must be based on the specific body structure and physical activity in the environment. Mind is always the body mind, while the initial cognition is always related to the body structure and the way of activity. Secondly, Lakoff and Johnson put forward the rational from the brain, body and the nature. Different biological bodies' anatomical structure determines their difference perceptions of the world. Perception and motion system of human beings plays a more important basis role in concept formation and reasoning. Because embodied cognition is one of the leading topics in the field of cognitive science, and the influence of interdisciplinary research background, theoretical divergence is inevitable. Foreign studies, in addition to theoretical contention, are more empirical research. From the Arizona State University, Columbia University, California University in San Diego, university of Manchester and the university of Cambridge and other colleges and universities and the Department of psychology and cognitive science department have established the embodied cognition research Laboratory of they make a comprehensive and in-depth exploration practice on embodied cognition. SJ Nasuto and Y Hayashi combine the current robotics with physical cognition. ${ }^{[10]}$ Specially, we should be paid to carry out a variety of education application projects, and research will be applied in the embodied cognition practice project. Learners study knowledge in the context of the specific problems, and experience knowledge through the embodied perception. The research of embodied cognition in foreign countries has been explored from the theoretical application to practice under the guidance of new technology and new media, and has been widely promoted, which provides some references and lessons for our projects such as future classroom, smart classroom.

\section{Influence of Embodied Cognition on Education}

In education, the body should be liberated. The liberated body and the learning brain can let the learners learn faster. Therefore, the physical nature of teaching theory, epistemology and methodology should be paid attention to. Embodied cognition comes from the book "Philosophy in the Flesh: The Embodied Mind and its Challenge to Western Thought", which is written by American linguist Lakoff and philosopher Johnson. They put forward three basic ideas on the basis of physical philosophy. [11]

Fen Dong's [12]"Classroom Teaching Strategy Research Based on Embodied Cognition Theory" and "Implication and Embodiment of Classroom Teaching Strategy Research on Primary School Chinese Teaching as the Example", Zhao Liu and the Shu Han's [13] "Embodied Cognition and the Enlightenment to Classroom Teaching", Yuanqing He and Xiao Zhou's, ${ }^{[14]}$ come from Anhwei Normal University, "The Classroom Teaching Research Based on Embodied Cognition", which mainly discusses the changes brings from body in the classroom so as to change the traditional teaching environment---clsssroom which can be reformed. Embodied teaching strategies are put forward and the position of body is enhanced in teaching. Nanchang Yang and Xiaoyan Liu's : 
"Embodied Teaching Design and Research of the New Orientation"[15], Jing Wang, Zhiwen Liu and Weidong Chen's "Future Classroom Teaching Design Characteristics: Embodied Cognition Perspective",[16] Peng Liu 's "Teaching Instructional Design Research Based on Embodied Cognition Theory ".[17] Both of them are new research to guide the direction of teaching design, teaching methods based on the study of embodied cognition theory. Not only that, embodied cognition also stresses that the body acts firstly before the study, but it must be separated from the action learning method. If we want to learn moral lessons, we firstly need to do a moral thing. Embodied cognition is very different from traditional teaching. Traditional teaching mainly focuses on classroom teaching, and teaching students' Ideological and moral theories and encouraging students to do it. Without real practice, learning outcomes are hard to be predicted, and learning feedback cannot be got.

\section{The Combination of VR Educational Games and Embodied Cognition}

\section{VR Education Game}

What is an educational game? What is a VR educational game? Educational games are games which have the meaning of education and can teach the players something. VR educational games refer to educational games based on virtual reality technology. It has been said that virtual reality technology will be the most promising technology in the field of education after multimedia and computer networks. ${ }^{[18]}$ So the educational game is now getting much attention, and all kinds of educational games have sprung up like mushrooms. B Hegarty and J Macdonald analyzed educational technology in a critical way. ${ }^{[19]} \mathrm{S}$ Gregory and B Gregory have studied the emergence of new educational technology, accompanied by the evolution of the application of 3D virtual reality in education. ${ }^{[20]}$ As Marc Prensky in "Digital game based learning" mentioned in the "learning in the entertainment, entertainment in the study". ${ }^{[21]}$ In recent years, VR educational games begun to gradually emerge the new education concept about innovation in the international community, which is run from "learn based on the game" to "gamification". Gee's "What Video Games Have to Teach Us about Learning and Literacy", which explores the mode of the game, will affect what kind of cognitive development. This paper deals with the video game in the field of learning can have great potential application, and also try to establish 36 game learning principles. ${ }^{[2]}$ Gangyao Zhang and Dejun Ma put forward the three trends of educational games in China now, and put forward that the evaluation and management of educational games in China are still missing, which needs further study. ${ }^{[23]}$ Tongju Wang described the important role of VR/AR on education and STEAM, and analyzes the effect of AR/VR on education, which will breed a new teaching mode and teaching method. ${ }^{[24]}$ Zhishi Zhang introduces the integration reality, and explores the relationship between VR/AR, and the learning environment that VR/AR faces to assists learners in coping with future education. ${ }^{[25]} \mathrm{But}$ VR/AR can be combined with our educational games. VR educational games can teach or help teaching, and people pay attention to VR education game's situational teaching and body movements, and study the significance of body movements on the education, which is not a new way of teaching.

\section{The Internal Relationship Between Embodied Cognition and VR Educational Games-Body Movements}

According to the theory of embodied cognition, we will find that using some gestures and actions in class can enhance students' interest and enthusiasm in learning, and the combination of body movements and human brain learning will make education easier. The player's behaviors and learning are a kind of be closely related and mutually dependent relationship. ${ }^{[26]}$ GARDNER H proposed three types of embodied education curriculum model, ${ }^{[27]}$ If VR educational games are combined with embodied cognition, unpredictable educational results will be achieved. In fact, this application will bring new directions and breakthroughs to our research. 


\section{Enlightenment and Thinking of VR Educational Games Based on Embodied Cognition}

The core of embodied cognition lies in the liberation of the body, and the importance of the body in the learning environment. It emphasis on perception and cognition, and learners mainly experience knowledge through the body's perception. In the implementation process of VR educational game, learners will enhance their learning effect through body language. Therefore, when designing VR educational games, we should pay attention to learning experience in real environment and feel the real simulation environment. In the VR educational game, we should focus on the role of the body, because body movements can improve the learners' interest in learning and greatly enhance their focuses. At the same time, it is also helpful for teachers to perceive the learner's learning effect and master the classroom situation through the body movements of the students.

\section{References}

[1] Haosheng Ye: submitted to Journal of Huazhong Normal University (HUMANITIES AND SOCIAL SCIENCES) (2011), In Chinese.

[2] Haosheng Ye: submitted to Psychosocial Science (2011), In Chinese.

[3] Xianjun Xu: submitted to Research on philosophy of science and technology (2007), In Chinese.

[4] Wei Meng: submitted to Communication of Dialectics of nature (2007), In Chinese.

[5] Qiwei Li: submitted to Journal of Psychology (2008), In Chinese.

[6] Haosheng Ye: submitted to Journal of Psychology (2011), In Chinese.

[7] Haosheng Ye: submitted to Development of Psychosocial Science (2010), In Chinese.

[8] Mengcheng Zhao and Huiting Wang: submitted to Research on theory and Application (2015), In Chinese.

[9] Wilson,M:Psychonomic Bulletin\&Review (2002), p. 625-626

[10] SJ Nasuto, Y Hayashi: Bio Systems, (2016), p. 22Lele Chen: submitted to Journal of Soochow University (EDUCATION SCIENCE EDITION) (2016), In Chinese.

[11] Lakoff G M,Johnson: Basic Books.(1999),p.3-36

[12] Fen Dong: submitted to Guide for Education (2013), In Chinese.

[13]Zhao Liu, Shu Han: submitted to Psychological technology and its application (2015), In Chinese.

[14] Yuanqing He, Xiao Zhou: submitted to Journal of Tung Lin College (2010), In Chinese.

[15] Nanchang Yang, Xiaoyan Liu: submitted to E-education Research (2014), In Chinese.

[16] Jing Wang, Zhiwen Liu and Weidong Chen: submitted to Research on Modern Distance Education (2014), In Chinese.

[17] Peng Liu: submitted to Educational technology and equipment in China (2015), In Chinese.

[18] Yuan Liu: submitted to Multimedia technology and its application (2016), In Chinese.

[19] B Hegarty, J Macdonald: Ascilite.(2014)

[20] S Gregory, B Gregory:Ascilite,(2014), p. 335-341

[21] Prensky, M. New York:McGraw Hill Press (2001)

[22] James Paul Gee:Palgrave Macmillan (2003)

[23] GangYao Zhang, Dejun Ma: E-education Research (2008), In Chinese. 
[24] Tongju Wang: Digital Education (2017), In Chinese.

[25] Zhishi Zhang:Modern educational technology (2017), In Chinese.

[26] Kan Tao:China Educational Technology (2011), In Chinese.

[27] GARDNER H,HATCH T: Educational Researcher (1989), p.4-9 